\title{
El diario entre dos temporalidades: de la periodicidad a la simultaneidad
}

\section{PORDANIEL MAZZONE}

mazzone@ort.edu.uy Facultad de Comunicación y Diseño, Universidad ORT Uruguay

Fecha de recepción: 20/9/2016

Fecha de aceptación: 25/10/2016

\section{RESUMEN}

Este trabajo aborda la disolución del concepto de diario, tras los pronunciamientos dedos instituciones periodísticas de referencia. El diario ha sido desplazado por el continuo informativo de los medios gráficos online, y deja atrás la segmentación periódica con que se designó tradicionalmente a los productos impresos. La temporalidad que llegó con los periódicos, empieza a cerrar su ciclo en la actual inmediatez. Aquí se describen algunos hitos del proceso que condujo a los diarios de su rol fundacional, a diluirse en las prácticas conversacionales que reconfiguran el ecosistema en base a nuevos contratos de comunicación. La periodicidad expresó al siglo XIX del mismo modo que la simultaneidad expresa al siglo XXI.

PALABRAS CLAVE: temporalidad, periodicidad, periodismo, periódicos, ecosistema.

\begin{abstract}
This article is focusing on the dissolution of the actual newspaper concept, after announcements made by two important journalistic Institutions. Print media has been displaced bycontinuum information of graphics online media, leavingbehind the typical periodical segmentation traditionally used by print products. The temporality that arrived with the newspaper begins to close its cycle in the actual immediacy. This work describes several inflexion points in the process that led newspapers from their foundational role towards the dissolution of the conversational practices, reconfiguring the ecosystem based on a new communication contract. Periodicity reflects the XIX century, as simultaneity does with the XXI century.
\end{abstract}

KEYWORDS: temporality, periodicity, journalism, newspaper, ecosystem. 


\section{INTRODUCCIÓN: DOS NOVEDADES SIGNIFICATIVAS}

"Si los debates provocados por el posmodernismo nos han enseñado alguna cosa, no es precisamente que
los procesos de desarrollo característicos de las sociedades modernas nos hayan impulsado más allá dela
modernidad, hacia una nueva y, de momento, indefinida era, sino que nuestras estructuras teóricas tradi-
cionales para la comprensión de estos procesos son, en muchos aspectos, tristemente inadecuadas".

John B. Thompson

"En el interior de una época no hay ningún punto de vista que permita contemplar la próxima".

W. Goethe

Cuando la novedad irrumpe, o bien anuncia lo inesperado-la aparición de las redes reticulares a fines de los años 60 puede ser un ejemplo-o bien ratifica una presunción que completa el sentido de un proceso abierto, esperable y aun inexplicado. Precisamente en setiembre de 2016 se presentaron dos novedades que responden a la segunda opción y anuncian el desplazamiento del diario y del rol hegemónico que ostentó entre los medios gráficos durante casi dos siglos.

El primero de los hechos tiene que ver con que la Newspaper Association of America (NAA), surgida en 1887 y con 2.700 socios en 2008 -en la actualidad cuenta con 2.000-, modificó su nombre, eliminando la palabra newspaper. El cambio, oficializado el 7 de setiembre de 2016, se fundó en que el concepto que identificaba a la publicación de información gráfica con el papel ha dejado de representar a la industria. El nuevo nombre de la asociación, News Media Alliance, mantiene la parte de la palabra que alude a la producción de noticias, pero eliminó la que designa el soporte.

Dicha circunstancia podría considerarse en forma aislada si en el mismo mes de setiembre no hubiera ocurrido otro hecho significativo y sintomático: el Vicepresidente del Grupo New York Times Media Company desde 1997, Michael Golden, declaró al diario La Nación de Buenos Aires que esa compañía ya no se define en base a la edición impresa del New York Times: "No somos un periódico que tiene una página web. Somos una compañía de medios de comunicación digital que saca un diario" (LaNación, 18/09/16).Amboshechos vienen precedidos por otro cambio de nombre con idéntico sentido: en 2009, La American Society of Newspapers Editors pasó a denominarse American Society of News Editors (Poynter, 2016).

Hace dos décadas que la edición de los diarios y periódicos impresos pierde peso relativo frente al continuo informativo que introdujeron las tecnologías digitales. Estos dos pronunciamientos, esperables y factibles, sumados al tercero de 2009, innovan en cuanto reconocen, al tiempo que refuerzan, una tendencia consolidada, y definen el nuevo marco de la industria que también registra modificaciones en la distribución y las costumbres de consumo por parte de los usuarios. 
En este acelerado acompasamiento del tiempo social y el de los medios, las más recientes formas asumidas por las mediatizaciones conducen a una simultaneidad que pone en cuestión -sino desnaturaliza-varias de las modalidades que legitimaron desde sus comienzos al diario y a los periodistas gráficos como referentes en la construcción social de sentido.

En ocasiones, los hechos anticipan respuestas que terminan de ordenar preguntas que no habían llegado a formularse por completo. De ahí que la aparición de un dato que quizá indique la inflexión en un ciclo, puede alumbrar el camino hacia el futuro, y también hacia el pasado, contribuyendo en su indicialidad a definir el escenario que transforma. Sabemos desde Marshall McLuhan que el ecosistema de medios no opera por eliminación, sino por agregación; de ahí que no corresponda apresurarse a extraer de las novedades enunciadas conclusiones más o menos categóricas: nada de lo dicho autoriza a especular con una presunta desaparición del periódico impreso, aunque sí a constatar el desplazamiento del papel como soporte hegemónico en el marco amplio de la transformación de los medios gráficos.

Lo concreto es que el impreso ya no representa a la industria en la forma ostensible que el concepto newspaper o diario -asociado implícitamente al papel y la impresión -enunciaba. Son movimientos que anuncian y sintetizan otros desplazamientos, por tanto inducen a interrogarse acerca de qué es en realidad lo que se mueve y conduce a nuevas estructuras sustitutivas.

\section{LA TEMPORALIDAD, UN CONCEPTO CLAVE DE LA MEDIATIZACIÓN}

Describir las circunstancias que rodearon la génesis de los periódicos impresos en simultaneidad con el desarrollo de las ciudades puede contribuir a la mejor comprensión del alcance de esa convergencia que no es una simple coincidencia. La sociedad industrial tuvo lugar en ciudades modernas que se estructuraron junto a los medios gráficos impresos en una nueva percepción del tiempo social caracterizada por "una acumulación de tiempos fragmentarios a causa del peso de los ciclos inducidos por la nueva organización económica y social" (Thérenty \& Vaillant, en Verón, 2013,pp. 230 y 231 ).

Este trabajo, que se propone explorar y establecer las condiciones que originaron el ciclo, tiene como antecedente una investigación realizada entre 2008 y 2010, cuyo objeto era la discursividad ciberperiodística, estudiada en términos comparativos entre el New York Times y el Huffington Post. Uno de los aspectos abordados en dicha investigación es la temporalidad introducida por el ciberperiodismo, pudiendo advertir, por ejemplo, que "la matriz de la portada determina el ritmo de rotación [que] según el criterio definido, se cuentan 5/6 ediciones diarias del Huffington Post y unas 15/16 ediciones diarias del New York Times, en términos promediales" (Mazzone, 2012, p. 108). 
Allí se explicaba que la disposición física de los elementos en la portada (layout) constituye una decisión discursiva que condiciona la función de cada uno de estos elementos y termina por condicionar el ritmo de rotación. Es decir que la distribución de elementos y su despliegue en la portada, la carga y recarga de novedades, y el ritmo con que rote el conjunto son elementos de una misma estrategia, más allá de la conciencia que se posea en el momento en que se adopten las decisiones (Mazzone, 2010).

En aquellos trabajos $(2010 ; 2012 a)$, junto a otro que abordó específicamente la "Periodicidad y actualidad en el Huffington Post" (Mazzone, 2012b), se describió el modo en que la matriz de la portada determina el ritmo de rotación de los cibermedios. Asimismo, se determinó que, pese a que la periodicidad marcada por la rotación, por su propia conformación hipertextual, dota al ciberperiodismo de la capacidad de "desarrollar un número de ediciones casi ilimitado a priori”, diferentes razones que varían para cada cibermedio, producto de sus propias macro-decisiones discursivas, terminan limitando y restringiendo aquellas posibilidades (Mazzone, 2012b).

El concepto de temporalidad ha sido un buen concepto pivote para escudriñar las sucesivas inflexiones de la discursividad gráfica y su gravitación en el decurso de las comunidades humanas. De ahí que la propuesta sea precisamente detenerse en algunos hitos ya estudiados académicamente, y en torno a los cuales existe un saber acumulado, para proyectar la observación en las configuraciones más recientes y actuales del ecosistema. Entre los ejes que Maingueneau (2009) establece como parámetros del concepto de temporalidad para los géneros discursivos, incluye el que denomina "una duración de caducidad esperada: se supone que una revista se lee durante toda la semana, un diario en el espacio de una jornada, pero un texto religioso fundador ( La Biblia, El Corán...) pretende ser indefinidamente leído" (2009, p. 57).

En aras de precisar las temporalidades según los sucesivos tipos de sociedad, en primer lugar habremos de situar el paso de las sociedades ágrafas u orales a las sociedades escriturales. En segundo lugar, el pasaje de las sociedades escriturales que utilizaron diferentes dispositivos previos a la imprenta y luego a las sociedades escriturales que conocieron los textos impresos en serie. En tercer lugar, el arribo a la periodicidad, con su ícono más característico, el diario. Finalmente, la imposición del continuo informativo que introduce unas condiciones en que tiende a establecerse una duración en que la caducidad esperada se reduce dramáticamente y tiende a desaparecer. Ese estadio de la simultaneidad será nuestro punto de arribo; en sus parámetros se intentará advertir y describir algunos cambios discursivos que, aunque incipientes, vuelven a alterar en forma significativa, como en la génesis escritural o en los propios orígenes industriales, los ritmos y comportamientos sociales. 


\section{EL ABANDONO DE LA TEMPORALIDAD ORAL Y LA ESCRITURA COMO NUEVA COMPLEJIDAD}

No es difícil imaginar que la escritura haya modificado radicalmentela percepción del individuo acerca de sí mismo con respecto a las sociedades ágrafas, dado que "el sapiens abandona definitivamente un cierto tipo de temporalidad" (Verón, 2013, p. 194). Es decir, cambia esencialmente el vínculo entre actores sociales, de modo quela distancia entre enunciación y reconocimiento, relativa a la permanencia de los enunciados en el tiempo, se dilata y expande. La nueva complejidad emergente debió resolver situaciones que desde el punto de vista de la mediatización se sintetizan en tres núcleos problemáticos: el problema del archivo, la materialidad y la circulación.

Abreviando mucho, digamos que "la acumulación (de cuerpos escritos) generó, por primera vez en la historia humana, el fenómeno del archivo" (Verón, 2013, p. 199). Debía resolverse qué hacer con los materiales generados y todo lo que-ahoralo sabemos-rodea a la idea de archivo, cómoy qué seleccionar, saber dónde se lo conserva y la cuestión del acceso al material cuando se lo necesita.

De la sola idea de archivo, cabe suponer que debió plantearse la segunda cuestión, que podríamos sintetizar en la de su materialidad, es decir, de qué modo arribó la sociedad al modelo manejable de objeto capaz de ser conservado en términos utilizables por las sucesivas generaciones.

La textualidad narrativa tenía, como una de sus principales características, la longitud, y por eso resultaba natural la búsqueda de una materialidad condensada, manejable, de esas narraciones, en relación con las múltiples circunstancias de la vida religiosa. Ahora bien, durante toda la Antigüedad anterior al cristianismo, esos relatos tuvieron una materialidad extremadamente inadecuada, el rollo. En la Antigüedad tardía aparece el cuerpo textual del códice, es decir, comienza a generalizarse la forma libro. Este cuerpo tuvo tanto éxito que acompañó, a partir de ese momento, toda la historia humana, y sigue estando entre nosotros después de unos dieciocho siglos (Verón, 2013).

Finalmente, la tercera circunstancia planteada por el advenimiento de la escritura sería la de su circulación, que es en definitiva la de su control, "dónde está, quién tiene acceso, quién puede negociar con sus contenidos y cómo. Así aparece el tercer aspecto fundamental del proceso de la mediatización: las condiciones de acceso, es decir, la dimensión dela circulación" (Verón, 2013,p.200).

Si se mirabien, los tres aspectos problemáticos que introdujo la escritura en la historia de la mediatización -archivo, materialidad y circulación- vuelven a ser críticos en la transición actualmente en curso. Pero avancemos despacio. En el próximo parágrafo nos detendremos en los tiempos de la mediatización en quelos medios buscaban-sin saberlo con exactitud-nuevasformas de persistir en el tiempo, que sustituyeran a la irregularidad y los encuentros puntuales con el público, por estatutos más apropiados a las nuevas condiciones sociales. 


\section{SOCIEDAD INDUSTRIAL: MEDIOS AL ENCUENTRO DELA NUEVA TEMPORALIDAD}

Decía Goethe que en el interior de una época no hay ningún punto de vista que permita contemplar la próxima; es decir, que las sociedades humanas se dirigen hacia nuevas situaciones que desconocen y que recién comprenderán una vez que las novedades otorguen inteligibilidad a los hechos y desarrollos pasados. En la lógica de los procesos sociales, el sentido último de los acontecimientos permanece oculto, hasta que su acumulación lo completa. Toda nueva época adquiere corporeidad y conciencia de sí, una vez que el puzle termina de estructurarse. Fue de ese modo que el arribo a la periodicidad terminó de explicar los múltiples procesos previos convergentes. Su hallazgo, como veremos producto de diversas variables, fue una suerte de factor ordenador que posibilitó el surgimiento de medios capaces de contener y expresar a los habitantes de las nuevas ciudades.

Si bien para Einsenstein (1994), tal como plantea Verón (2013), “la invención de la imprenta fue una revolución que durante mucho tiempo pasó inadvertida debido a su complejidad y a su carácter multidimensional" (2013, p. 211), el semiólogo argentino subraya que en realidad "todos los momentos clave en la historia de la mediatización [son] complejos, es decir, no admiten interpretaciones en términos de secuencias lineales causaefecto, y son multidimensionales, es decir, alteran los mundos sociales y sus relaciones" (p. 211).

Esa complejidad multidimensional atravesó los siglos que mediaron entre la invención de la imprenta de tipos móviles y la instalación de la periodicidad. No sólo debía despertarse el interés por leer noticias sobre acontecimientos como la Guerra de los Treinta Años, entre 1618 y 1648 (hasta entonces las noticias habían circulado en forma oral); también era imprescindible que surgiera un público capaz de leer o que al menos quisiera escuchar las noticias leídas, y también que disminuyera la censura del poder- que como en el caso británico fue muy dura para impedir que se transgredieran las normas impuestas por la monarquía-. Fue necesario, además, y con el transcurrir del tiempo, que las autoridades liberaran de impuestos el tráfico de información y se eliminaran otros obstáculos administrativos, así como debieron gestarse las condiciones para la incorporación de la publicidad que permitiera a los públicos masivos acceder a los medios emergentes.

Los nuevos medios que inauguraban el ecosistema industrial presuponían la ciudad, la industria, el ahorro, el capital, la producción excedente y, por lo tanto, el consumo, el comercio y la inversión. Los procesos que condujeron a completar este escenario, explican la aceleración del tiempo social que finalmente desembocó en la construcción de la periodicidad que las aldeas inconexas y escasamente dinámicas de la época preindustrial difícilmente habrían alcanzado. 
Para Thompson fue:

Otra manera en que el desarrollo de la imprenta transformó los modelos de comunicación a principios de la Europa moderna, dando lugar a una variedad de publicaciones periódicas que informaban de acontecimientos y transmitían información de carácter político y comercial (1998, p. 93).

Según Thompson, los papeles de noticias, desde sus primeros intentos en los siglos XVIy XVII, alteraron profundamente el orden anterior a la imprenta, organizado en torno a cuatro redes de comunicación por toda Europa:

Una [de ellas] extensa y controlada por la iglesia católica (...), otras redes establecidas por las autoridades políticas de Estados y principados (...), un tercer tipo de redes vinculado a la expansión dela actividad comercial (...), finalmente, la información también se transmitía en poblaciones y pueblos a través de redes de comerciantes, vendedores y artistas ambulantes, como los narradores de cuentos y los cantantes de romances (1998, pp. 93 y 94 ).

Estas redes resultaron afectadas entre los siglos XV y XVII por dos desarrollos. En primer lugar, algunos Estados comenzaron a establecer servicios regulares de correo cuya utilización, de manera progresiva, fue generalizándose. El segundo aspecto que afectó profundamente a las redes de comunicación establecidas a principios de la Europa Moderna fue la aplicación de la imprenta a la producción y difusión de noticias. Poco después del advenimiento de la imprenta a mediados del siglo XV, comenzaron a aparecer folletos informativos, carteles y hojas de papel impresas de varios tipos. Se trataba de una mezcla de declaraciones oficiales $\mathrm{u}$ oficiosas sabidas de decretos gubernamentales: tratados polémicos, descripciones de acontecimientos particulares, tales como confrontaciones militares o desastres naturales y narraciones sensacionalistas de fenómenos sobrenaturales o extraordinarios, como gigantes, cometas y apariciones. Estos panfletos u hojas informativas tenían carácter irregular o se emitían una sola vez. Se imprimían por millares y los vendían en la calle los charlatanes yvendedores ambulantes. Las publicaciones periódicas de noticias einformación general empezaron a aparecer en la segunda mitad del siglo XVI, aunque los comienzos de los periódicos modernos se ubican en las primeras dos décadas del siglo XVII, cuando los periódicos de noticias aparecen regularmente cada semana con cierto grado de fiabilidad (Thompson, 1998).

Por su parte, Verón subraya que la imprenta posibilitó la aparición de

Otras materialidades discursivas, estas sí radicalmente nuevas, que acompañaron a la proliferación del libro y que estaban destinadas a transformar profundamente la relación de los textos con la temporalidad social: los panfletos, primero, y los "papeles de noticias", después, representaron, por decirlo así, en un mundo escritural y con un desplazamiento premecánico de las personas, el "en vivo y en directo" de la primera modernidad (2013, pp. 219 y 220$)$. 
Los panfletos, esos papeles cuyo sentido se agota prácticamente en el acto de enunciación, ya que apuntan a pronunciarse sobre un fenómeno puntual, coyunturaly, por tanto pasajero, constituyen una delas estaciones del itinerario seguido por los papeles impresos hasta llegar a la periodicidad.

Satisfecha esa urgencia a través de la intervención que consiste el acto panfletario, el contrato de comunicación se desvanece, aunque pueda dar lugar a la secuencia de denuncia-réplica/contrarréplica (...). Podemos decir que el tiempo, en este caso, tiene un carácter puntual, está presente en el contrato enunciativo como instante y no como dimensión (Verón, 2013, p. 224; bastardilla en el original).

Esta dimensión temporal existente en los fenómenos mediáticos nos interesa específicamente a los fines de este trabajo. Las nuevas multitudes urbanas, tan bien descriptas por Benjamin (1986) a través del análisis de las narrativas de Edgar Poey Charles Baudelaire, son las que protagonizaron los cambios que modificarían la forma en que la sociedad empezó a percibirse a sí misma: “Angustia, repugnancia, miedo, suscitó la multitud metropolitana en los primeros que la miraron a los ojos. En Poe la multitud tiene algo de bárbaro" (Benjamin, 1986, p. 107). Por su parte, cuando Benjamin cita a Baudelaire, dice que "habla del hombre que se sumerge en la multitud como en un reservoir de energía eléctrica. Y lo define enseguida, describiendo la experiencia del shock como un caleidoscopio dotado de conciencia" (1986, p. 107).

Quizá porque lo sobrevivió 17 años (Baudelaire murió en 1866 y Poe en 1849), o porque vivió toda su vida en París, lo cierto es que para Baudelaire la multitud es algo tan intrínseco "que en su obra se busca inútilmente una descripción de ella", como subraya Benjamin (1986, p. 100). La mirada de Poe, en cambio, revela el desconcierto que le provoca la multitud urbana londinense y parece una buena aproximación a lo que debe imaginar un usuario de medios del siglo XXI para intentar entender cómo era el habitante de la ciudad industrial que protagonizó el primer acercamiento a los periódicos impresos.

\section{EL NACIMIENTO DEL DIARIO SIGNADO POR EL ARRIBO A LA PERIODICIDAD}

Describir la mediatización de la temporalidad implica observar las formas que asume la detención del tiempo en las gramáticas de los distintos lenguajes, ejemplificada en la fotografía para la imagen y en la grabación para el sonido. En cuanto a lo escritural/gráfico, la temporalidad debe buscarse en el itinerario descripto por la secuencialidad en que la gráfica se fue organizando a través de sucesivos estatutos, cada uno de los cuales buscó y encontró sus públicos puntuales en medio de la irregularidad de sus emisiones. 
Los códices antiguos en los quela Antigüedad estampó su legado, los panfletos ylibelos, los almanaques y los distintos papeles de noticias que emitían los distintos poderes fueron el producto de distintos momentos de la historia, cuyo estatuto respondía a necesidades precisas, de emisores y públicos específicos. La periodicidad es un punto de arribo en que convergen nuevos públicos y no menos nuevos anunciantes que le otorgaron sostenibilidad a los nuevos medios que el idioma español bautizó como diarios. En este segmento se exploran las razones por las cuales el diario nace vinculado íntimamente a esa temporalidad e incluso contribuye a gestarla. Es decir que nace tan singularizado por ese momento de la materialización de la temporalidad en la comunicación humana, quela propia época marcó suidentidad nombrando a los nuevos medios con los atributos de la medida del tiempo.

Es claro que si bien se considera a la periodicidad ya consolidada a partir de la convergencia publicidad/medios impresos en la década de 1830, se trata de una construcción cuya génesis remite al siglo XVII. La aparición de publicaciones periódicas fue sobre todo un fenómeno centroeuropeo, desarrollado en una extensa zona en torno a la diagonal Amberes-Venecia, coincidente con el eje del Rhin, en torno al que se desarrolló la imprenta. Dicha área fue el origen primero de la revolución comercial y de la expansión de los mercados y las ciudades, asícomo del despliegue de los primeros servicios regulares de correos, de la circulación de las noticias y de las luchas políticas y religiosas de la Reforma luterana y de la Contrarreforma (Guillamet, en Barrera, 2004).

El mismo autor consigna que:

La tipografía e impresión manual apenas cambiarían hasta bien entrado el siglo XIX y las tiradas estuvieron condicionadas además por el elevado coste de la suscripción, al alcance únicamente de los sectores alfabetizados de la nobleza, el clero y los comerciantes de las ciudades (2004, p. 72).

Es decir que si bien existían hojas periódicas y pequeñas gacetas de noticias editadas con cierta regularidad una o dos veces a la semana, la periodicidad con alcance masivo en términos de minorías urbanas significativas datan de mediados del siglo XIX, en consonancia con los orígenes del diario. La escritura como "primer proceso que combinó la autonomización de los signos lingüísticos respecto de la fuente que lo produce, con la persistencia del mensaje en el tiempo" (Verón, 2013, p. 145) proyectó su autonomía en diversas formas de la temporalidad a lo largo de la historia previa a la periodicidad, como por ejemplo en las ya vistas entregas fugaces de los panfletos o los diversos papeles de noticias. Pero es en la potencialidad que desenvuelve el periódico que aquella autonomía -obviamente inadvertida en las épocas en las que prevaleció la aperiodicidad-adquiere nuevas posibilidades transformadoras. La regularidad permitió así a los periódicos impresos iniciar una conversación que estableció vínculos que el primer habitante de las ciudades desconocía. 


\section{EL PRIMER CONTRATO DE COMUNICACIÓN: ENTRE LA FINALIDAD INFORMATIVA YLADE CAPTACIÓN}

El primer contrato de comunicación sólo pudo celebrarse a partir del momento en que irrumpe lo que Charaudeau denomina una "tensión permanente" entre las dos finalidades de un medio: "informativa y de captación" (2003, p. 259). Y es obvio que hasta la periodicidad, si bien en las épocas previas podía hablarse aún en términos espasmódicos de información, difícilmente existiera la voluntad consciente de captar un lector más allá del instante: tal pretensión sólo puede existir cuando en la mente del editor está presente la voluntad y la posibilidad efectiva de volver a tomar contacto regular con el lector. Y es claro que tanto lo uno como lo otro dependió en gran medida de las condiciones que maduraron a mediados del siglo XIX.

Desde la perspectiva actual se comprende que ninguna agenda pública o mediática podía fundarse en aquellas materialidades discursivas previas a la periodicidad, cuyo sentido se agotaba una vez transcurrida la coyuntura que las había motivado. La nueva realidad social necesitaba configurarse en presencia de medios estables, de producción responsabley circulación organizada. Difícilmente la producción social de sentido fuera a realizarse sin un nuevo tipo de medios investidos de la legitimidad inherente a su nuevo rol. Por ello no debe pasar inadvertido el dato de que el diario -los periódicos impresos en general-surgiera en el marco de la nueva temporalidad de la mediatización. Lo llamativo es quela propia denominación singularice simbólicamente el vínculo del diario con la temporalidad.

$\mathrm{Ni}$ la radio ni el cine o la televisión -los grandes medios del siglo XX-se designan en alusión a lo temporal, probablemente porque se ubicaron en la evolución de los medios en momentos en que la periodicidad era ya un asunto laudado. Denominados desde su funcionalidad, y unidos desde las redes de broadcasting, lo radiofónico y lo televisivo inauguraron la simultaneidad del vivo y directo. Con la transmisión radial de eventos en tiempo real a partir de la década de 1930se abría una etapa de coincidencia del tiempo social y mediático que se constituiría en el preámbulo histórico de la actual inmediatez. Complementaron a los medios gráficos y, de hecho, los acotaron en el marco del nuevo ecosistema.

La línea de tiempo que transcurre entre la consolidación de los diarios del siglo XIX como fundadores del ecosistema industrial, hasta la proliferación de medios que actualmente se distribuyen a través de múltiples canales y redes, informa de un recorrido intenso e impredecible, a priori, en su incesante apertura de nuevas y sucesivas interrogaciones. Algunos pocos grandes diarios como The Times (Londres, 1785) nacieron cuando todavía la periodicidad estaba en construcción. Había productos gráficos mensuales, quincenales, semanales, bisemanales y hasta esporádicos, pero nadie que se hubiera atrevido a com- 
prometerse en la entrega de una edición de un mismo medio todos los días, en forma regular y sostenida, había, hasta ese momento, logrado sobrevivir.

Hubo un día en que el diario fue lo nuevo y debió ganarse su espacio a expensas de desprenderse del lastre que le impedía proyectarse. Inicialmente debió distanciarse del negocio dela imprenta; incluso hasta comienzos del siglo XX todavía se hablaba inercialmente de "libertad de imprenta" sin terminar de consolidarse la fórmula "libertad de prensa" o "de expresión". También debió ganarse el respeto que le negaron en sus prolegómenos las primeras figuras de la Ilustración. Para Voltaire, las gacetas que precedieron a los diarios eran "la narración de bagatelas" (Barrera, 2004, p. 74); para Rousseau un "libro periódico" no era más que "una obra efímera sin mérito alguno y sin utilidad, cuya lectura desdeñada y menospreciada por las gentes de letras no sirve sino para dar a las mujeres y a los tontos vanidad sin instrucción" (Barrera, ídem); y Diderot escribió en la Enciclopedia que "todos estos papeles son el pasto de los ignorantes, el recurso de los que quieren hablar y juzgar sin leer, el azote y la repugnancia de aquellos que trabajan" (Pierre Albert, en Barrera, 2004, p. 74).

Finalmente, debió independizarse del libro. Todavía en la primera mitad del siglo XIX la apariencia de los diarios continuó limitada por los cánones típicos de la edición de libros: la sobriedad de la columna corrida sólo se vio alterada por la multiplicación del número de columnas. No había alardes tipográficos ni se podían hallar otros elementos gráficos que no fueran las líneas o filetes para separar unos textos de otros (Barrera, 2004). Pero por sobre todas las cosas debió encontrar el camino hacia la rentabilidad, para que el producto pudiera ser adquirido por los lectorados urbanos que tuvieran, además, capacidad de consumo de los productos que el diario ponía a su consideración a través de la publicidad.

Éste fue el descubrimiento decisivo de Emile de Girardin, quien advirtió intuitivamente que la publicidad y el periódico impreso eran potencialmente convergentes, y en 1836 dotó a su diario parisino La Presse de los primeros avisos comerciales, así comenzó al ciclo de las publicaciones gráficas a precio de tapa accesible. En ese apareamiento que le aportóla necesaria sostenibilidad, el diario quedó investido como silencioso acompañante de la transición psicológica de los pobladores de las aldeas en habitantes complejos de las nuevas ciudades tumultuosas.

La alianza entre el diario y la publicidad parece otro ciclo que ahora está en vías de agotarse. Y esa situación que pone en dificultades al modelo de negocios clásico, informa a su vez sobre la falta de autonomía que el diario exhibió desde sus orígenes. Alguien debía pagar la cuenta de las costosas estructuras que requería la calidad informativa servida con regularidad, en una ecuación que paradojalmente, demandaba audiencias atractivas para las grandes firmas publicitarias. Esa tensión entre el mercado y el servicio público constituye una de las marcas fundacionales (incluso podría ser una hándicap del origen) 
que condujeron a equilibrios dificultosos y enfrentamientos con frecuencia de fuerte carga emocional entre las divisiones que atienden ambos polos de esa tensión en la interna de los medios de prensa.

No todo lo que ocurría durante el sigloXIX se vinculaba a la comunicación, pero los cambios comunicacionales se formalizaron entrelazándose con múltiples procesos simultáneos que dinamizaron las décadas iniciales del siglo XIX en los comienzos de una nueva época caracterizada por la industrialización. De ese conjunto de datos discernimos tres líneas - una cierta concepción de la temporalidad, el desarrollo de los papeles de noticias y la naciente publicidad-, todas emergentes de las nuevas ciudades industriales y coincidentes en hacer de ese momento del siglo XIX el marco del origen de los periódicos impresos.

En el último tramo se releva brevemente el tránsito de los medios impresos entre las dos mutaciones ocurridas del tiempo social: una en el siglo XIX y la otra actualmente en curso.

\section{LA DURACIÓN DEL DIARIO SE AGOTA JUNTO CON EL CONTRATO DE COMUNICACIÓN DE LA SOCIEDAD INDUSTRIAL}

A partir de los comienzos escriturales se emitieron y difundieron las grandes verdades de la filosofía y la religión, proyectadas en su alcance mucho más allá del momento de su enunciación. Con la invención de la imprenta de tipos móviles se revolucionaría el universo de la reproductibilidad gráfica. No obstante, para que surgiera la industria editorial sería necesaria la ley de Copyright Act (Londres, 1710), ya que hasta entonces no resultaba atractivo invertir en ediciones que cualquiera podía copiar. Tampoco habría industria periodística hasta que la publicidad no financiara la llegada masiva de los nuevos medios a las multitudes urbanas a mediados del siglo XIX. Son estas nuevas circunstancias las que, según Verón, transformaron "los papeles de noticias en los primeros diarios modernos como uno de los síntomas preanunciadores, entre otros, de la Segunda Revolución Industrial" (Verón, 2011, p. 300).Y agrega que Thérenty y Vaillant ubican la cuestión de la periodicidad en el marco general de una mutación del tiempo social:

Antes la vida parecía seguir las lentas evoluciones de la naturaleza, la religión o la historia dinástica (...). Ahora (en el transcurso del siglo XIX) la vida se presenta como una sucesión de momentos y una superposición de ritmos, como una acumulación de tiempos fragmentarios a causa del peso acumulado de los ciclos inducidos por la nueva organización económica y social: ciclos de actividad política y parlamentaria, de la industria y de los transportes modernos, de los medios, de la vida ciudadana, etc. Esta nueva relación con el tiempo se acompaña de una mayor movilidad en el espacio: los medios de comunicación se modernizan, los viajes se generalizan (...). Una de las formas más visibles de esta civilización del ritmo generalizado es el desarrollo, en el siglo XIX, de la prensa periódica (Verón, 2011,pp. 300 y 301). 
En el momento actual abundan los indicios de agotamiento del contrato de comunicación basado en la alianza de diarios y agencias publicitarias. Este debilitamiento del ciclo informa a su vez de cierta dependencia del periodismo -esa hipoteca de origen a la que nos referimos antes como hándicap- que no se presenta en la fundación de otras industrias mediáticas como por ejemplo el cine, cuyos insumos han sido sufragados íntegramente por los usuarios. Nada de esto implica un juicio de valor entre dos medios incomparables entre sí. Su mención sólo obedece a que contribuye a delinear otras características del viejo contrato de comunicación que también se diluyen y explican el cambio de ciclo.

Los problemas que afectan al diario y lo desplazan en cuanto medio gráfico hegemónico, no provienen solo de factores intrínsecos. En medio de la configuración del ecosistema informacional de medios, las nuevas audiencias muestran indicios crecientes de debilitamiento objetivo de sus lazos de adhesión hacia los medios tradicionales. Un informe de Grzegorz Piechota, investigador asociado de Harvard Business School, establece que 30\% de las visitas que reciben los websites de 37 grandes editores (el $80 \%$ con 10 millones de visitantes únicos por mes, o más) las reciben desde Facebook (Nieman Lab, 2016).

Esta situación parece evidenciar una superposición de contratos de comunicación concurrentes en la medida en que el objetivo de ambos tipos de plataformas -medios y redes- es la captación de los usuarios. Para los medios tradicionales, se trata nada menos que delas audiencias queles han pertenecido desde siempre. Para las redes de networking, que se han transformado en espacios ineludibles de vehiculización de contenidos, obtener el concurso de los usuarios es crucial en cuanto son los generadores de esos mismos contenidos.

El escenario que está configurándose parece sugerir que el viejo contrato entre el periódico impreso y su público se encuentra en vías de disolución antelas modalidades socio-técnicas emergentes, que permiten a las audiencias consultar diversos medios en forma simultánea y a su vez realizar múltiples actividades en las redes de networking, todo ocurre sin salir de la red a la que los medios referentes acuden precisamente en busca de las grandes audiencias. Es cada vez más habitual que el usuario recuerde en qué red obtuvo una información, pero sin que pueda precisar el medio que la produjo.

Mientras los medios tradicionales presentan dificultades para incorporarse con éxito a la cultura digital - por las razones ya relevadas-, las redes de networking, surgidas a partir de 2004, parecen sintonizar con los estilos de época ylas condiciones que requiere el nuevo ecosistema de medios. A partir de 2015, Facebook lanzó Instant Articles, al que luego siguió Facebook Live, iniciativa que imitó Periscope de Twitter y Accelerated Mobile Pages, de Google, entre otros, en una tendencia a fundar espacios capaces de atraer a medios y usuarios, en busca de su producción de contenidos.

El movimiento fue exitoso, al punto de que los medios -carentes de alternativas propias- terminaron incorporándose masivamente a unas o a otras, 
o incluso a todas las posibilidades existentes. Se trata de un fenómeno que requiere tratamiento específico y si se lo menciona en este trabajo es porque tendrá -ya tiene- incidencia en el objeto de análisis. En particular, uno de los aspectos en que se expresa la nueva relación de las audiencias con las redes de networking es el desplazamiento de ciertas minorías de usuarios hacia posiciones de co-creación y coproducción de información, un movimiento que en su hibridez, propende a invadir zonas hasta este momento reservadas a profesionales del periodismo.

Emily Bell (2016), directora fundadora del Tow Center for digital journalism at Columbia Journalism Schoool, establecido en 2010, sostiene que el impredecible curso del live streaming nos ha tomado escasamente preparados. Desde hace dos décadas, dice, nos dirigimos hacia la utilización de las capacidades del broadcasting que el mobile abarata, y según parece hemos arribado a destino. Bell cuenta además que durante la guerra de Irak, en 2003, estuvo a cargo de un website de información, pero ahora, en los últimos meses, ha visto más muertos o gente muriendo a través de Facebook. Nosotros, la audiencia, estamos a un clic de todo y a expensas de ver demasiados cuerpos destrozados, como en la rambla de Niza. La inmediatez de los medios, las expectativas creadas a partir de la convicción de que ahora podemos estar en todas partes, está cambiando la forma en que experimentamos las crisis y aun nuestra propia mortalidad (Bell, 2016).

De modo que el antiguo broadcasting inaugurado por la radio y la televisión en la primera mitad del siglo XX, ha vuelto potenciado por las redes de networking, no ya exclusivamente en manos profesionales, sino a disposición de aficionados que inauguran un estatuto de consecuencias impredecibles en el marco de la comunicación simultánea.

Durante la vigencia del ecosistema industrial, el monopolio de la emisión radicaba en los medios informativos, cuyos equipos adoptaban las decisiones editoriales acerca de cómo, cuándo y en qué condiciones de edición se liberaba la información. A partir de Facebook Live y de Twitter/Periscope, la información se produce y circula -al menos potencialmente- en modalidades de simultaneidad que abren, a su vez, inéditas condiciones de consumo.

La dimensión del cambio que introduce a las audiencias a ciertos formatos de la construcción del acontecimiento (al menos en eventos de interés masivo) queda de manifiesto cuando se lo compara con el proceso técnico que históricamente ha demandado esa misma producción a los profesionales. Para que se pueda señalar un acontecimiento, es necesario que se produzca una modificación en el estado del mundo fenoménico generadora de un estado de desequilibrio, que esa modificación sea percibida por sujetos (o que consideren que ha habido una modificación), lo cual produce un efecto de "realce", y que esa percepción se inscriba en una red coherente de significaciones sociales que producen un efecto de impregnación (Charaudeau, 2008). 
Es decir que entre los hechos y su destino de consumo en las audiencias mediaban históricamente dos operaciones, como la de realce e impregnación, a través de las cuales las organizaciones mediáticas trataban la materialidad discursiva en situaciones de edición. De ese modo, no sólo escogían cuidadosamente el material a emitir, sino que además creaban cierta distancia temporal entre los hechos y su distribución al público.

Las nuevas posibilidades y disponibilidades tecnológicas en manos del público crean un nuevo escenario en que esa distancia se adelgaza y hasta desaparece, provocando nuevas experiencias que ponen a prueba a los públicos y sus capacidades de metabolización. Existan o no esas capacidades, nos encontramos ante un nuevo estatuto en la cobertura de la inmediatez, en medio de una nueva mutación de la temporalidad.

\section{HACIA LA CONFIGURACIÓN DE UN ESCENARIO DE CONDICIONES INCIERTAS}

En este marco, el contrato de comunicación proveniente del ecosistema industrial tiende a desvanecerse. Como no se trata de un escenario consolidado sino en pleno desarrollo y por tanto en movimiento, ignoramos por el momento las formas que asumirá en sus fases culminantes. Y si bien sabemos que el propio concepto de diario está cuestionado, también ignoramos hacia qué modelo se orientarán las empresas editoras de diarios actualmente existentes. Como vimos, el Grupo New York Times, una organización de origen industrial nacida en 1851, ya se define como una compañía de medios digitales que edita un diario.

Por lo pronto, la fuerte tensión entre las redes de networking y los medios -sean tradicionales como el New York Times o el Washington Post o nuevos como BuzzFeed o el Huffington Post- por la captación de los contenidos generados por los usuarios, modifica las formas industriales de la mediatización que prevalecieron históricamente. La hibridación - por lo menos parcial- de las audiencias, ya no sólo destinatarias de la información, sino activas animadoras de los diversos formatos conversacionales que transforman el ejercicio periodístico, son factores concurrentes al cambio en el contrato de comunicación.

No hay por qué apresurarse a establecer paralelismos, pero los dos procesos en que hizo foco este trabajo -el origen del diario y su agotamiento como concepto hegemónico-, aun separados por casi dos siglos, lucen, en sus aspectos esenciales, suficientemente similares como para dejar de advertir que el itinerario del diario ha transcurrido entre dos mutaciones de la temporalidad social.

El nuevo ciclo parece signado por sucesivas y múltiples convergencias hipermediáticas. Los lenguajes comenzaron a mezclarse en forma indistinta, de modo que los medios gráficos utilizan sonido e imagen, así como los 
medios de sonido y audiovisuales hacen lo propio con la gráfica. La fuerte impronta de cambios introducidos por la nueva temporalidad resulta reforzada por la tendencia creciente hacia el uso de dispositivos móviles. Al cierre de este trabajo se informa que por primera vez los conectados desde móviles $(51,3 \%)$ superan a los conectados desde equipos fijos $(48,7 \%)$, dato que informa de la cada vez mayor movilidad -quizá volatilidad- de las audiencias (Stats Counter, 2016).

Si en los orígenes de la industrialización los habitantes de las nuevas ciudades resultaron sorprendidos por la fragmentación del tiempo y la sucesión de ritmos, nuestras ciudades altamente mediatizadas de la sociedad informacional aparecen sacudidas por una multiplicidad creciente de estímulos que volatilizan la atención y vuelven a modificar la temporalidad social. La aparición -por demás exitosa- de redes efímeras del tipo Snapchat se inscribe en lógicas coincidentes con nuevos estilos de época.

Quizá por algún tiempo le sigamos llamando diarios o periódicos a los medios gráficos online, pese a que informan durante 24 horas los siete días de la semana. También le seguimos llamando libro al e-book. Y como prueba máxima de que no alcanzan los cambios generacionales para alterar las inercias que los usos sociales imponen, recordemos que seguimos diciendo "sale el sol", casi cinco siglos después de Copérnico. 


\section{REFERENCIAS}

Barrera, C. (coordinador) (2004). Historia del Periodismo Universal. Barcelona: Ariel.

Bell, E. (2016, 17 de julio). The unpredictable course of live streaming has caught us unprepared. En The Guardian. Recuperado de https://www.theguardian.com/ media/2016/jul/17/live-streaming-violent-events- crisis-facebook?CMP=twt_gu

Benjamin, W. (1986). Sobre algunos temas en Baudelaire. En Sobre el programa de la filosofía futura (pp 89-124). Barcelona: Planeta.

Burke, P. (2009). Cultura popular en la Europa moderna. Madrid: Alianza Editorial.

Casasúsi Guri,J.M.(2002).Nuevos conceptos teóricosparala investigaciónen periodismo digital. Barcelona:Universidad Pompeu Fabra. Recuperado dehttp://fama2.us.es/ fco/digicomu/cap11.pdf

Charaudeau, P. (2003). El discurso de la información. La construcción del espejo social. Barcelona: Gedisa.

Eisenstein, E. (1994).La revolución de la imprenta en la Edad Moderna Europea. Madrid: Akal.

Golden, M. (2016, 18 de septiembre).Michael Golden: "Somos una compañía de medios digitales que saca un diario". La Nación. Recupera de: http://www.lanacion.com. ar/1938974-michael-golden-somos-una-compania-de- medios-digitales-quesaca-un-diario

Maingueneau, D. (2009).Análisisdetextosdecomunicación. Buenos Aires:Nueva Visión.

Mazzone, D. (2010). Imágenes del lector en el ciberperiodismo. Estudio comparativo de la discursividad de The New York Times y The Huffington Post(tesis de Maestría). Universidad de San Andrés-Grupo Clarín.

Mazzone, D. (2012a). Huffington Post vs. New York Times ¿Quéciberperiodismo? Buenos Aires: La Crujía.

Mazzone, D. (2012b). "Periodicidad y actualidad en el Huffington Post". En Encuentro Latinoamericano de Facultades de Comunicación (FELAFACS), Universidad de Lima, Perú. Recuperado de http://fresno.ulima.edu.pe/felafacs.nsf/ PonenciasDetalle/eje1-37

Nieman Lab (2016).Survey of large publishers: 30 percent of our website visits come from Facebook. Recuperado dehttp://www.niemanlab.org/2016/09/survey-of- largepublishers-30-percent-of-our-website-visits-come-from-facebook/ 
Poynter Institute (2016, 5 de septiembre). Recuperado dehttp://www.poynter.org/2016/ the-newspaper- association-of-america-is- changing-its-name/428934/

Stats Counter Global Stats (2016). Recuperado de http://gs.statcounter.com/press/ mobile-and-tablet-internet-usage-exceeds- desktop-for-first-time-worldwide

Thompson, J. B. (1998). Los media y la modernidad. Una teoría de los medios de comunicación. Barcelona: Paidós.

Verón, E. (2011). Papeles en el tiempo. Los cuerpos efímeros. Buenos Aires: Paidós.

Verón,E. (2013).Semiosissocial2. Ideas, momentos, interpretantes. Buenos Aires: Paidós.

\section{IDENTIFICACIÓN DEL AUTOR:}

Daniel Mazzone es Magíster en Periodismo por la Universidad de San Andrés (Buenos Aires). Catedrático de Periodismo Digital y Coordinador Académico de Periodismo y Contenidos Digitales de la Universidad ORT Uruguay. Es integrante del equipo de redacción de la revista Diálogo político, de la Fundación Konrad Adenauer y miembro del Consejo Editorial de la revista L.I.S. Letra. Imagen. Sonido. Ciudad Mediatizada, de la Facultad de Ciencias Sociales de la Universidad de Buenos Aires. Además fue editor de Internacionales en los diarios La República, El Día y El Observador, y editor periodístico de El País digital desde fundación hasta 2005.

Es autor de los libros de cuentos: Primer bando (1986), Custer y Bernabé en el País del Urú (1988), Jam Session en la Posta del Ángel (1990), Desamores (1993). También es autor de los libros de ensayos: Desenfocados (2005), Hispanoamérica: interpelación alosfundadores (2011), Huffington Postvs. New York Times ¿Qué ciberperiodismo? (2012) y Cibermedios y lectores en busca de un modelo (2013).

\section{REGISTRO BIBLIOGRÁFICO:}

Mazzone,D. (2016, diciembre). El diario entre dostemporalidades: dela periodicidad ala simultaneidad. En InMediaciones de la Comunicación, 11, pp. 211-228. Revista dela Escuela de Comunicación, Facultad de Comunicación y Diseño, Universidad ORT Uruguay, República Oriental del Uruguay. 